\title{
Concepções e Modos de Viver em Família: A perspectiva de Mulheres Lésbicas que Têm Filhos
}

\author{
Aline Nogueira de Lira ${ }^{1}$ \\ Normanda Araujo de Morais \\ Georges Daniel Janja Bloc Boris \\ Universidade de Fortaleza
}

\begin{abstract}
RESUMO - Investigaram-se as concepções e modos de viver em família de quatro mulheres lésbicas que têm filhos. Utilizou-se uma entrevista aberta para coleta de dados e a análise baseou-se no método fenomenológico crítico. Os resultados mostraram que: (a) as estratégias para acesso à parentalidade (adoção, coparentalidade e relações heterossexuais anteriores) são diversas e ora reproduzem o binarismo heterossexual, ora o desnaturalizam; (b) a família foi caracterizada como um espaço afetivo e de proteção; e (c) a legalização do casamento foi percebida como uma forma de garantir direitos sociais e jurídicos. Ressalta-se a pluralidade e complexidade dessas famílias, ao mesmo tempo em que se mostra a inviabilidade de se traçar uma concepção única sobre as famílias homoparentais.
\end{abstract}

Palavras-chave: família, homoparentalidade, lésbica, casamento, gênero

\section{Conceptions and Ways of Family Living: The Perspective of Lesbian Women Who Have Children}

\begin{abstract}
The conceptions and ways of family living of four lesbian women who have children were investigated. An open interview was used for data collection and its analysis was based on the critical phenomenological method. The results showed that: (a) strategies for access to parenting (adoption, co-parenting and previous heterosexual relationships) are diverse and they both represent the heterosexual binarity, and distort its nature; (b) family was characterized as an affective and protective space; and (c) the legalization of marriage was perceived as a way to ensure social and legal rights. The plurality and complexity of these families are highlighted, at the same time the impracticality to draw only one conception on families with homosexual parents is shown as well.
\end{abstract}

Keywords: family, homosexual parents, lesbian, marriage, gender

As transformações culturais, políticas, econômicas e científicas vividas pelas sociedades ocidentais contribuíram para a emergência de profundas mudanças nas concepções e práticas das relações familiares (Uziel, 2007). Consequentemente, ainda que prevaleça a concepção hegemônica de família nuclear - monogâmica, heterocêntrica e patriarcal (Szymanski, 1998), esse modelo vem, nas últimas décadas, sendo desconstruído com base em várias transformações no cenário sociocultural da família contemporânea (Castells, 1996/2010). Diversos arranjos familiares se apresentam na contemporaneidade e promovem questionamentos significativos nas relações de parentesco, de filiação e de definição da diferença entre os sexos. Põese em xeque, assim, a ideia de que o homem e a mulher se completariam apenas pela função reprodutiva e que, juntos, necessariamente, proporcionariam um ambiente mais favorável à socialização das crianças do que as famílias homoparentais (Arán \& Corrêa, 2004).

1 Endereço para correspondência: Av.Washington Soares, 1321, Bloco B, sala N13, Edson Queiroz, Fortaleza, Ceará, Brasil. CEP. CEP 60.811905.E-mail: aline.lira09@hotmail.com
É nesse contexto de pluralidade que se destaca a família homoparental - arranjo familiar que abrange as relações parentais entre lésbicas ou gays e seus possíveis filhos (Santos, Scorsolini-Comin, \& Santos, 2013; Uziel, 2007). Este modelo ganha notoriedade exatamente porque rompe com a sacralização do modelo heterocêntrico tradicional e destitui um princípio essencial da constituição familiar: a diferença sexual (Passos, 2005; Roudinesco, 2003). Mulheres que amam mulheres e homens que amam homens elaboram projetos de conjugalidade e de parentalidade e desafiam os padrões que seriam garantia de "normalidade" e de felicidade das famílias tradicionais: a necessidade de duas pessoas de sexos diferentes, unidos pelo matrimônio, com seus filhos concebidos biologicamente e a convivência heterossexual (Uziel, 2007). Portanto, os novos arranjos familiares constituídos por mães lésbicas e pais gays revelam o declínio das relações de parentesco e parentalidade exclusivamente pautadas nos laços consanguíneos, como formas exclusivas e privilegiadas de procriação, embora ainda predominantes nos casamentos contemporâneos. Os laços afetivo-sexuais são o principal instrumento para a manutenção dos vínculos, sustentando não apenas a conjugalidade homossexual, mas também a homoparentalidade (Zambrano, 2006). 
Os estudos sobre as famílias homoparentais embasam algumas discussões importantes: em uma perspectiva mais sociológica, estudiosos apontam que a formação da família constituída por gays e lésbicas é parte de um processo social e cultural complexo e assenta-se, principalmente, nas diversas transformações acerca da família e da sexualidade que têm acontecido nas últimas décadas, especialmente nos países do Ocidente (e.g. Castells, 1996/2010; Vespucci, 2014). Exemplos dessas mudanças referem-se, por exemplo, ao aumento dos divórcios e separações conjugais; ao aumento dos índices de coabitação (morar junto sem oficializar a união); à redução nos índices de natalidade; à crescente autonomia das mulheres em relação ao seu comportamento reprodutivo; a movimentos sociais como o feminismo e a luta pela garantia de direitos das pessoas LGBT; à crescente proliferação e visibilidade das relações entre casais do mesmo sexo, entre outras. Além disso, com o processo de individualização da família, em curso desde o fim do século XIX, a satisfação de seus membros passa a ser mais valorizada nas relações familiares do que o seu caráter institucional (Gato, 2014).

Em um enfoque mais antropológico, as pesquisas sobre as famílias lideradas por pais/mães gays/lésbicas têm expandido as noções de parentesco para além do significado biológico e incorporado os laços afetivos como importante aspecto constitutivo das redes familiares (e.g. Weston, 1991). Nessa contextura, Butler (2003) faz um questionamento a respeito dos sistemas de parentesco: "O parentesco é sempre tido como heterossexual?" (p. 221). A esse respeito, a autora explica que "existem e persistem relações de parentesco que não se enquadram no modelo de família nuclear" (Butler, 2003, p. 221). Ou seja, existem relações que são norteadas pelas concepções biológicas e não biológicas, funcionando mediante regras não formalizáveis, indo além do alcance jurídico. Sob esse contexto, por exemplo, o casamento e os laços de sangue já não determinam os laços de parentesco, colocando em xeque as sociedades heteronormativas, especialmente quando se apresentam as famílias homoparentais. Estas, ao questionarem as leis consideradas "naturais", responsáveis pelo resguardo da inteligibilidade humana, são vistas como socialmente perigosas para as crianças (Butler, 2003).

Já em uma perspectiva psicológica, os estudos sobre a homoparentalidade têm discutido o funcionamento e a dinâmica familiar dos casais do mesmo sexo, enfatizando os pontos fortes das relações parentais e conjugais, além de procurar responder aos questionamentos acerca da capacidade dos pais/mães gays/lésbicas para criarem os seus filhos (Goldberg \& Gartrell, 2014). Salienta-se, todavia, que as evidências científicas das pesquisas realizadas ao longo dos últimos anos têm sugerido que crianças criadas em lares liderados por pais/mães do mesmo sexo não sofrem prejuízos em seu desenvolvimento psicossocial por causa da orientação sexual de seus pais/mães (Lira \& Morais, 2016).

Mesmo com a crescente visibilidade social, jurídica e acadêmica, as redes familiares constituídas por lésbicas, gays e bissexuais são gerenciadas sob diferentes graus de adversidade, especialmente pelo contexto homofóbico e heterossexista em que vivem. Na medida em que rompem com os arranjos familiares aos quais a sociedade está costumada, muitas polêmicas e controvérsias surgem sobre a legitimidade e da competência de gays e lésbicas para a criação de famílias e de seus filhos (Tarnovski, 2004). É importante pensar que há algum tempo, para tornar-se pai ou mãe, era necessário casar-se ou unir-se com uma pessoa do sexo oposto ao seu. Atualmente, porém, as pessoas podem escolher se querem ter filhos e como desejam que os filhos cheguem às suas vidas.

Hoje, gays e lésbicas têm diferentes possibilidades de ter seus filhos, destacando-se as seguintes (Passos, 2005; Uziel, 2007): (a) a família recomposta, na qual um membro do casal, ou ambos, traz(em) filhos de relações heterossexuais anteriores à descoberta, ou antes, de assumirem a orientação afetivo-sexual homossexual; (b) a coparentalidade que se refere ao arranjo familiar criado por gays e lésbicas que se associam com parceiros do outro sexo (homossexual ou heterossexual) para procriar, com ou sem relações sexuais; (c) a adoção, realizada pelo casal ou por apenas um dos membros; e (d) com os novos recursos tecnológicos de reprodução humana, por exemplo a inseminação artificial alcançada com o sêmen do doador, no caso de um casal de lésbicas, ou no do casal de homens, uma mãe substituta que concebe o filho com o sêmen de um dos companheiros do casal ou de um doador e com os óvulos de uma doadora. Esses arranjos familiares são excelentes exemplos para apontar como as pessoas, em situações específicas, inauguram formas de viver em família. Além disso, essas práticas contribuem para a mudança das noções contemporâneas sobre o que é a família.

Considerando o caráter sócio-histórico da família, bem como os aspectos subjetivos que colaboram para a sua construção, a família, seja heterossexual ou homoparental, pode ser pensada sob diversas perspectivas, assumindo uma multiplicidade de sentidos e formas (Vilhena et al., 2011). Por exemplo, no estudo qualitativo realizado com 12 casais do mesmo sexo que tinham adotado filhos ou que tinham projetos para fazê-lo, Machin (2016) constatou que ter um filho a partir do projeto conjugal foi visto como importante para o reconhecimento e afirmação da família; além disso, os participantes revelaram que a eleição pela adoção legal teve como principal motivação o receio de que outros arranjos parentais pudessem gerar certas vulnerabilidades para $o$ casal e para o filho/a, dada a força dos laços de sangue em detrimento do vínculo afetivo e social ou do dispositivo legal. Percebeu-se, ainda, que o compromisso social preponderou na percepção da adoção. Pontes, Féres-Carneiro e Magalhães (2015), por sua vez, analisaram qualitativamente a vivência de nove mulheres lésbicas que concretizaram a maternidade biológica com o auxílio das novas tecnologias reprodutivas. Entre os vários achados, as autoras informaram que o desejo por garantir os laços consanguíneos com os filhos foi a prioridade para a concretização da maternidade, o que parece reproduzir o modelo idealizado de família nuclear, com ênfase nos laços de sangue.

Nas relações homoparentais femininas, objeto deste estudo, as mulheres, ao se relacionarem afetiva e/ou sexualmente com outras mulheres, põem em questão a necessidade do par heterossexual como instância legitimadora das relações familiares e conjugais e, ainda, a afirmação da dominação masculina em relação ao universo feminino. 
Além disso, os filhos chegam às suas vidas de modo que, muitas vezes, não correspondem a esse modelo naturalista. Algumas mulheres lésbicas, por exemplo, exercem a parentalidade por adoção ou geram seus filhos mediante inseminação artificial ou outras tecnologias reprodutivas. Em alguns casos, mulheres geram os filhos com os óvulos das suas parceiras ou ainda com sêmen doado por homens conhecidos ou desconhecidos ${ }^{1}$. Esses são exemplos que parecem desafiar a ordem essencialista, ultrapassando o modelo da diferenciação sexual, ao desvincular a vivência parental do par heterossexual e da ordem de procriação.

Ressalta-se, no entanto, que a primazia do vínculo biológico na edificação dos laços de parentesco, muitas vezes, é um difícil desafio para um casal de mulheres (Donavam, 2000). Pesquisas nacionais e internacionais apontam que, em alguns casos, a mãe que gera biologicamente a criança parece ter mais direitos e responsabilidades sobre ela (Biblarz \& Savci, 2010; Corrêa, 2012). Não por acaso, muitas mulheres buscam estratégias para evitar esses conflitos, como, por exemplo: utilizam as tecnologias reprodutivas, em que uma delas gera o filho com o óvulo da outra; uma das mulheres engravida com o sêmen de algum parente da sua companheira, como forma de garantir a consanguinidade do filho com as duas mães; ou quando lutam pela possibilidade de ter os dois nomes das mães na certidão de nascimento da criança (Corrêa, 2012; Passos, 2005).

Uma das concepções naturalizadas socialmente e que colabora para tornar a experiência de parentalidade das mulheres lésbicas mais desafiadora ancora-se nas relações de gênero e da própria sexualidade referente ao mito do amor materno, anunciado por Badinter (1985). Nessa compreensão, existe uma crença intocável de que a maternidade e o amor ao filho são instintivos e inerentes à natureza do feminino. Nesse sentido, "a mulher é feita para ser mãe, e mais, uma mãe boa" (Badinter, 1985, p. 14). A ordem, portanto, é ser mulher, feminina e boa mãe. A partir dessa ideia, a maternidade tornase um desafio para o casal de lésbicas, por se tratar de duas mulheres, pois a mulher que gera, instintivamente, ama mais o filho, cabendo à parceira, muitas vezes, apenas a tarefa de "auxiliar" nos cuidados da criança. No entanto, Badinter (1985) problematiza a concepção de uma suposta "natureza feminina". Para isso, defende a ideia de que a maternidade é uma construção sócio-histórica e que, portanto, a noção de uma mulher-mãe, tal como se conhece hoje - propensa ao sacrifício natural e ao amor universal e instintivo pelos filhos - nem sempre existiu na história da humanidade.

A conjugalidade entre os casais do mesmo sexo, assim como a parentalidade, evoca polêmicas e posicionamentos, muitas vezes ambíguos, na sociedade contemporânea, sendo, recorrentemente, marcada por ideologias familiaristas e naturalistas. Tidos como intrusivos no vocabulário conjugal, os amantes do mesmo sexo ultrapassam o sistema

1 De acordo com a resolução $\mathrm{n}^{\circ} 1.957 / 10$ do Conselho Federal de Medicina (CFM), as clínicas de reprodução assistida devem trabalhar sempre com a doação anônima de sêmen. No entanto, na prática, algumas mulheres lésbicas optam por fazer a inseminação artificial "caseira" ou mesmo por ter relações sexuais com um parente da sua parceira, a fim de garantir que a criança tenha laços biológicos com as duas mulheres. essencialista da diferença sexual presente nas famílias nucleares: aliança, filiação e sexualidade. Constitui-se, portanto, como impensável no imaginário social e até ininteligível no vocabulário amoroso, causando certo incômodo ao falar das relações entre casais do mesmo sexo (Costa, 1992).

A reflexão contemporânea sobre a construção social da conjugalidade dos casais do mesmo sexo é interpelada por duas questões cruciais: a primeira aponta para o reconhecimento social e jurídico das uniões homossexuais principalmente no âmbito do Poder Jurídico; e o segundo ponto refere-se às discussões em torno das afirmações de que relações amorosas estáveis entre pessoas do mesmo sexo constituem uma modalidade familiar conjugal que tem ganhado visibilidade no Brasil e no mundo ocidental (Castro, 2007; Mello, 2005).

A reivindicação jurídica e social da conjugalidade homoerótica, sobretudo no Brasil, tem assumido posicionamentos distintos (Castro, 2007). Para alguns setores do movimento homoerótico, a luta pela legitimação do casamento implica a busca de normalização familiar, sucumbindo à lógica de dominação que oprimiu os gays e as lésbicas por anos. Em outra perspectiva, exclama-se que o reconhecimento da conjugalidade homoerótica contribui para a subversão do sistema patriarcal, colaborando para derrubar a repressão sexual e flexibilizar as fronteiras sexuais. Por último, essa reivindicação aponta para a "reestruturação da família, e a ressignificação de conceitos como - amor, sexualidade, gênero, poder e até mesmo do sentido de identidades" (Castro, 2007, p. 90).

A ambiguidade se mostra, portanto, porque a legitimação da conjugalidade entre pessoas do mesmo sexo passa pela desconstrução do imperativo que vincula conjugalidade, sexualidade e reprodução. Ao mesmo tempo, ao dar estatuto de igualdade a casais do mesmo sexo e casais heterossexuais, vincula-se a ideia de normalização, desconsiderando o caráter singular das diversas formas de amar e de constituir famílias. Esse processo de normalização da família pelos caminhos da heterossexualidade, muitas vezes, direciona e alimenta o estigma que correlaciona a homossexualidade às patologias que pouco a pouco são desconstituídas.

E diante desse contexto de mudanças e discussões em torno da temática das famílias homoparentais que o presente estudo teve como objetivo investigar as concepções e modos de viver em famílias das mulheres lésbicas que têm filhos. Com a crescente visibilidade da homoparentalidade, torna-se relevante compreender os sentidos que as mulheres atribuem às vivências parentais e ao casamento/união estável, de modo a ampliar as noções de família e contestar as concepções naturalizadas centradas no modelo de família heterossexista e patriarcal. Dar visibilidade a essa temática permite a criação de um espaço de discussões e reflexões no contexto acadêmico e de questionamento do sistema ideológico hegemônico que prescreve a heterossexualidade como a norma que rege as relações familiares. 


\section{Método}

\section{Participantes}

Participaram deste estudo quatro mulheres lésbicas com idades entre 33 e 46 anos, residentes em Fortaleza, CE. Os critérios de inclusão foram: assumir-se como lésbica e ter filha/o(s). Na sequência, tem-se uma breve descrição das participantes. Visando ao sigilo da identidade, optou-se pela adoção de nomes fictícios.

Maria e Joana. Maria (33 anos, profissional liberal) e Joana (37 anos, funcionária pública), formam um casal e vivem em união estável há, aproximadamente, seis anos. Com três anos de relacionamento, oficializaram judicialmente a relação mediante um contrato de união estável. Mobilizadas para serem mães, empreenderam juntas o projeto de adotar Pedro, ainda recém-nascido, e que, no momento da entrevista, encontrava-se com 6 meses de vida. A criança passou pelo processo oficial de adoção e na sua certidão de nascimento constam os sobrenomes das duas mães. Ressalta-se, ainda, que Maria viveu um casamento heterossexual por nove anos, antes do relacionamento com Joana.

Simone. Simone (34 anos, analista de produção tem um filho, João ( 8 anos), fruto de uma relação heterossexual. Sua companheira, Júlia, tem dois filhos - José (8 anos) e Joaquim (14 anos), também concebidos em um casamento heterossexual, anterior à relação homossexual. Esta é uma família recomposta, em que ambas, após finalizarem relações conjugais, passaram a conviver juntas com seus filhos. Sobre a vivência conjugal, Simone e Júlia moravam juntas há 6 anos e, ao efetivarem o contrato de união estável, após 5 anos de relacionamento, este foi homologado e tornou-se uma certidão de casamento.

Após o contrato de união estável, Júlia passou a ter a Guarda Provisória de João, compartilhando com Simone a parentalidade do filho. Tanto o contrato de união estável como a guarda de filho foram realizados em meados de 2010, quando Simone foi esfaqueada por um homem por motivações homofóbicas. Simone enxergou a possibilidade de vir a falecer e passou a se questionar como seu filho ficaria diante dessa situação. Para não deixá-lo desamparado, Júlia assumiu a guarda de João.

Patrícia. Patrícia (46 anos, profissional da área de saúde, professora) tem um filho. Ricardo (15 anos). Patrícia viveu em união estável com Lia por 5 anos. Com 3 anos de relação, resolveram ter um filho. Contudo, especialmente Lia tinha o desejo de gerar a criança e, desse modo, resolveram que ela engravidaria do irmão de Patrícia, como uma forma de garantir que as duas seriam mães "legítimas" da criança, ao terem laços consanguíneos com elas. Neste sentido, Patrícia é a mãe (madrinha) e tia biológica de Ricardo. Aos 2 anos de idade do filho, elas se separaram e o filho ficou sob os cuidados de Lia, acontecimento que trouxe sofrimento para Patrícia. Salienta que Ricardo tem uma convivência com o pai. Atualmente, Patrícia vive em união estável com Jane e tem uma enteada, Camila (19 anos), que reside com as duas.

\section{Instrumento}

$\mathrm{O}$ instrumento utilizado para levantamento de dados foi uma entrevista fenomenológica aberta (Amatuzzi, 1993), a qual partiu da seguinte pergunta disparadora: "como você tem vivenciado a relação com o(s) filho(s)?" A análise da entrevista centrou-se nas questões que investigaram a parentalidade, porém o tema da concepção de família foi um tema emergente e que mereceu ser discutido de modo mais aprofundado nesse artigo.

\section{Procedimentos}

O projeto de pesquisa foi submetido ao Comitê de Ética da instituição de origem dos autores e aprovado (Parecer 151.678). Buscou-se, portanto, seguir todos os critérios éticos relacionados à pesquisa com seres humanos, de acordo com a Resolução n. 196/96 do Conselho Nacional de Saúde, que vigorava até então.

Após a aprovação do projeto de pesquisa, teve início o contato com as participantes. Inicialmente, contatou-se uma mulher que foi indicada pela rede de contatos informais da primeira autora. Em seguida, por meio do método snowball (bola de neve), identificaram-se mais duas participantes. Por fim, a quarta colaboradora foi indicada por um Centro de Referência LGBT, existente na cidade de Fortaleza. Elas foram entrevistadas individualmente, sendo que duas dessas colaboradoras formavam um casal (Maria e Joana) e cada uma delas participou de dois encontros, dada a necessidade de aprofundamento dos dados emergidos ao longo da primeira entrevista. As outras duas (Simone e Patrícia) participaram, cada uma, de apenas uma entrevista.

\section{Análise dos Dados}

Realizou-se de forma indutiva, sendo que as categorias emergiram a posteriori, e foram discutidas com base na literatura da área. A análise dos dados baseou-se no método fenomenológico crítico desenvolvido por Moreira (2004) e que tem como etapas: (a) apreensão do sentido da totalidade das entrevistas: os dados das entrevistas são transcritos e leituras múltiplas e exaustivas são realizadas, de modo a se ter uma percepção global das falas das colaboradoras; (b) divisão do texto nativo em movimentos de acordo com o tom da entrevista: esses tons se referem, por exemplo, aos trechos das entrevistas que abordam as mesmas temáticas, ou temas de maior relevância; (c) análise descritiva dos significados que emergiram em cada movimento: sistematizase e descreve-se os temas emergentes dos diversos momentos das entrevistas, na tentativa de identificar e compreender os vários significados da experiência homoparental; e (d) "Saída dos parênteses": retorna-se aos objetivos do trabalho, buscando um diálogo entre os resultados da pesquisa e a discussão teórica até aqui apresentada. 


\section{Resultados e Discussão}

No universo familiar aqui investigado, as mulheres revelaram ricas experiências sobre as concepções e os modos de viver em família. Uma vez que ainda impera no imaginário social a concepção de família associada à tríade heterossexualidade/casamento/procriação, foram eleitos três temas emergentes que ajudaram a compreender melhor as concepções de famílias das participantes: (a) Estratégias de acesso à parentalidade, evidencia os caminhos eleitos pelas mulheres entrevistadas para acessarem à parentalidade; (b) Familia: Um lugar de afeto e proteção, caracteriza-se pela definição do que é família para as participantes; e (c) Do contrato de união estável ao casamento civil, assinala a ênfase na legalização da relação conjugal para a constituição do projeto familiar descrito pelas entrevistadas.

\section{Estratégias de Acesso à Parentalidade}

As estratégias que as mães lésbicas empreenderam para exercer a parentalidade refletem as concepções que elas têm acerca de suas famílias. Desse modo, este tema emergente tece comentários sobre as motivações e negociações das participantes para se tornarem mães.

Duas das entrevistadas, Maria e Joana, escolheram a adoção como caminho para se tornarem mães. Corroborando achados de estudos anteriores, as motivações para a adoção dessas participantes estavam atreladas ao compromisso social (e.g. Meletti \& Scorsolini-Comin, 2015): cumprir a missão de fazer o bem e oferecer um lar para uma criança. Dessa forma, a concepção de parentalidade das entrevistadas estaria atrelada à ênfase nas relações sociais e afetivas que se estabelecem entre os seus membros:

Pra mim, adotar um filho passa por uma questão de idealismo exacerbado. Que egoismo é esse se tem tantas crianças sem lar e eu posso ser essa família para essa criança? Esse é o meu sentimento, a minha fé na solidariedade universal. (Joana)

Outra coisa interessantíssima que a gente optou pela adoção é: eu podia ter um filho, ir num banco de sêmen e engravidar. E ai, eu geraria aquela criança. E de alguma forma, eu estaria mais próxima da criança do que a minha companheira. Se acontecesse com a Joana, seria da mesma forma. Ai se cogitou: então eu engravido do óvulo da Joana, aí as duas tão participando, ou o contrário. Ai a gente disse: mas por que fazer isso se tem tanta criança que precisa de um lar, que precisa de amor, e a gente pode adotar uma criança? E em adotando, nós estamos exatamente na mesma proporção (...). E não tem discussão: eu sou mãe cem por cento; ela é mãe cem por cento. Perfeito! (Maria)

Todavia, especialmente na fala de Maria ("eu podia ter um filho, ir num banco de sêmen e engravidar. E aí, eu geraria aquela criança. E de alguma forma, eu estaria mais próxima da criança do que a minha companheira"), paradoxalmente, pode-se identificar a presença de uma concepção essencialista, em que se tem a primazia do vínculo biológico na edificação dos papéis parentais e a valorização da cultura procriativa inscrita no feminino (Arán \& Corrêa, 2004; Badinter, 1985). Nessa concepção, cabe à mulher a tarefa de gerar biologicamente um filho, amá-lo e garantir- lhes os cuidados e a felicidade (Corrêa, 2012). Apesar de, nas sociedades contemporâneas ocidentais, esse modelo essencialista estar sendo cada vez mais questionado, em virtude dos novos papéis e das novas atribuições sociais que as mulheres assumem, ainda ronda, no imaginário social, o atributo da maternidade como parte da natureza feminina. A concepção essencialista é marcada por leis da Biologia e passa pela ideologia do sangue, ao supostamente transmitir componentes físicos e também morais de uma linhagem (Uziel, 2007). Nessa perspectiva, o lugar da mãe é balizado por uma compreensão naturalizada de que mãe é a que gera (Badinter, 1985). Dessa forma, o vínculo biológico tem mais força do que os laços afetivos e sociais. Esse parâmetro naturalista parece ser um desafio a ser enfrentado pelas famílias homoparentais e também pelas famílias por adoção (Donavam, 2000).

As entrevistadas Simone e Patrícia, por sua vez, escolheram caminhos diferentes da adoção para ter filhos. Simone, por exemplo, revelou que, na tentativa de ser aprovada pela família, resolveu viver um relacionamento heterossexual, no qual engravidou.

Eu não queria ser sozinha no mundo. Eu queria alguém, então tive o João. Engravidei do João, só que quando eu tava com três meses de grávida, eu disse pra ele que o estava deixando, que não dava certo. Porque eu tinha tentado, mas que tava no meu limite. (Simone)

Simone parece ter significado a vivência de ter um filho mediante o sentimento de solidão em que se encontrava, decorrente da discriminação e da exclusão de seus familiares pelo fato de ser lésbica. Para viver as relações homossexuais, precisou morar sozinha e distanciar-se de sua rede familiar. O papel da mãe de um filho gerado via relação heterossexual foi o modo que ela encontrou para tornar invisível o papel da lésbica e, nesse sentido, sentir-se acolhida e pertencente a uma realidade social e familiar (Ben-Ari \& Livni, 2006). Dessa forma, buscou "escapar" dos preconceitos familiares e sociais, bem como do próprio preconceito internalizado, aderindo ao modelo socialmente aceito como norma: o par binário homem/mulher.

Para realização do projeto de ter filhos, Patrícia escolheu, junto com a sua ex-companheira - Lia - a opção de ter um filho, utilizando-se da relação sexual com a finalidade de procriação. Lia foi quem engravidou, uma vez que esta sinalizou o desejo de gestar a criança, como também passar pela experiência de ter relações sexuais com um homem. A relação sexual com fins reprodutivos é uma prática que acontece nas famílias lésbicas. Nessa situação, as mulheres negociam fazer sexo com os homens (amigos, parentes, ou mesmo desconhecidos), deixando claro (ou não) o seu projeto de engravidar (Corrêa, 2012). Para Patrícia, a opção pela relação sexual e não pela inseminação artificial, decorreu do seguinte aspecto: " $E$, a questão da inseminação a pessoa precisa tomar muito hormônio, tem todo um trabalho. Então é muito mais prática ser de uma forma natural, do que você fazer uma inseminação" (Patrícia).

De acordo com Patrícia, a forma natural de conceber um filho é realizada quando uma mulher decide engravidar a partir de relações sexuais com um homem. Na sua fala, podese perceber a força do modelo de diferenciação sexual como fundamento que rege as relações familiares - heterossexuais 
e homossexuais. Essa compreensão parece legitimar e naturalizar o par heterossexual como o modelo a ser seguido pelas famílias (Arán \& Corrêa, 2004). Pesquisas apontam que o modelo de coparentalidade parece ser percebido como o ideal para realização do projeto homoparental (Grossi, 2003; Tarnovski, 2010). Nesse sentido, segundo aponta Grossi (2003), uma das fantasias mais presentes entre jovens lésbicas é a realização da parentalidade mediante a inseminação do esperma do cunhado, ou seja, do irmão da sua companheira. Isso garantiria a consanguinidade do filho - com traços físicos e emocionais da família - bem como garantiria um lugar socialmente legitimado dentro de ambas as famílias, já que a criança também tem laços de sangue com os tios, avós e primos. Ter uma família com duas linhagens (a da mãe que gera e da outra mãe, via o material genético do irmão) parece ser um aspecto relevante para algumas famílias homoparentais (Grossi, 2003).

Ao eleger o irmão como o pai do seu filho, Patrícia teria um laço sanguíneo com a criança gerada pela companheira, o que a deixaria em um lugar mais seguro. A participante relatou, ainda, que já havia acompanhado muitos problemas de famílias lésbicas em que, por exemplo, diante da separação das parceiras, a mãe que não gerou sumia da relação. Refletia, também, sobre o fato de o filho ter uma mãe biológica e como ela ficaria na situação de outra mãe, já que não existiam leis que a protegessem na relação com a criança?

Ter uma companheira que tinha um filho biológico, e como era que eu iria ficar nessa história, como é que ia criar essa criança? Não tinha legislação nenhuma naquele momento que protegesse e aquela criatura ia dizer: não, a mãe sou eu. E eu ia ser o que? Não ia ser nada, né? (Patrícia)

A naturalização social da maternidade e o estranhamento social daquele que "auxilia" nos cuidados com os filhos - seja o pai ou, no caso da homoparentalidade feminina, a mulher que não gerou a criança - reforça a ideia de que quem gera tem um vínculo de maior proximidade e, portanto, tem mais responsabilidades e direitos sobre os filhos. Dessa forma, a decisão de quem deve engravidar, muitas vezes, é uma situação complexa presente nas famílias lésbicas, uma vez que a mulher que gera parece ter mais direitos sobre a criança (Corrêa, 2012). Conforme já mencionado, essa concepção parece estar atrelada ao mito do amor materno e a questões de gênero. Cabe à mãe a tarefa de dar à luz uma criança e ser a mantenedora dos cuidados e do amor ao filho, ao mesmo tempo em que a outra parte da relação fica à parte do processo parental. Patrícia, portanto, escolheu o irmão para ser o pai de seu filho como forma de avalizar seus direitos como mãe da criança, uma vez que isso garantiria o laço sanguíneo com ela, que, desse modo, teria um vínculo familiar com Ricardo.

Porém, ainda que tivesse laços de sangue com o filho Ricardo, quando este tinha 2 anos, Patrícia e Lia se separaram e a sua ex-companheira ficou com a guarda total do filho - fato que foi vivenciado com muito sofrimento por Patrícia. Sob uma perspectiva histórica, na época em que isso aconteceu, não havia qualquer legislação ou projeto de lei que garantisse direitos institucionais às famílias lésbicas. Ao conceberem os filhos, seja pela reprodução sexual ou por meio de adoção, constaria na certidão de nascimento deles, apenas o nome de uma das mães (sempre o da mãe biológica). Como mãe biológica, avalizada por leis naturalizadas da
Biologia, as leis jurídicas lhe outorgavam o poder sobre as crianças. À outra mãe cabia, então, a tarefa de auxiliar a sua parceira nos cuidados com o filho.

A partir dos relatos das mulheres entrevistadas ficou evidente como elas deram significados muito particulares aos seus projetos parentais. Dessa forma, mesmo em meio aos ditames sociais, que valorizam e põem ênfase no binarismo heterossexual como a ordem que rege as relações familiares, ainda assim, essas mulheres conseguiram realizar o seu projeto de ser mãe. Foi exatamente no embate entre os condicionantes sociais e o modo como se implicaram nas suas escolhas, que essas mulheres forjaram dialeticamente os seus projetos parentais e familiares.

\section{Família: Um Lugar de Afeto e Proteção}

A diversidade de arranjos familiares presente na sociedade contemporânea permite relativizar a família, apontando-a como uma instituição construída socialmente, deslegitimando a aparente naturalidade da família nuclear como o único modelo a ser seguido, mas têm em seus contornos a historicidade e o caráter contínuo de transformações culturais e subjetivas (Uziel, 2007; Wagner, Tronco, \& Armani, 2011). Dessa forma, as definições mais tradicionais de família já não contemplam a variedade de conceitos e significados que as pessoas atribuem às suas experiências familiares, como será visto mais adiante.

Nas entrevistas aqui analisadas foi possível perceber que a definição de família está atrelada, fundamentalmente, às práticas cotidianas estabelecidas entre os seus membros, sendo o amor, o cuidado, a proteção e a dignidade os principais valores presentes nas concepções de família (Meletti \& Scorsolini-Comin, 2015; Zambrano, 2006): "E familia é amor. É afeto. (...) como ele não foi concebido [biologicamente], o amor foi o que concebeu ele" (Maria); "Família é um porto seguro, família é o seu alicerce, família é o seu lugar de volta. (...) É aquele condão que você sabe que sempre vai contar na vida. Os risos e as gargalhadas, de uma familia de verdade (...). É o meu ninho" (Maria); "Mas é refúgio, sabe? (...) Então, hoje minha família é tudo pra mim. É o meu refúgio. (...) é como se não existisse ninguém lá fora" (Simone).

Verifica-se, portanto, que a definição de família é norteada por uma ética que privilegia as questões afetivas dos seus membros (Passos, 2005; Zambrano, 2006). Nesse sentido, os vínculos socioafetivos prevalecem e norteiam as definições das relações familiares dessas participantes.

Outro aspecto relevante observado nas concepções das mulheres é a valorização do lugar de proteção e de segurança da família. Mesmo na contemporaneidade, a vida privada familiar continua sendo vista como um lugar de proteção e de segurança. Institui-se como um ninho: refúgio caloroso e lugar de proteção das agressões externas (Perrot, 1993). Apesar das inúmeras mudanças por que a família passou nas últimas décadas - aumento dos divórcios e separações, inserção da mulher no mercado de trabalho, advento das novas tecnologias reprodutivas -, no século XXI, ainda se continua a reivindicar a família como um valor seguro, ao qual ninguém quer renunciar (Roudinesco, 2003). Ela é engendrada pela priorização do sentimento e pela exigência afetiva e sexual 
entre os membros envolvidos, sendo, portanto, um lugar de abrigo e aconchego. Nas famílias homoparentais, o espaço privado da família, como um lugar de proteção, parece ganhar ênfase exatamente pelas dificuldades ligadas ao preconceito e à discriminação relacionados às suas orientações sexuais (Rodriguez \& Paiva, 2009).

A colaboradora Joana descreve como função social da família promover o bem-estar de seus membros e da sociedade:

Então, o que mais caracteriza a nossa familia é o afeto e a dignidade, em prol do bem comum, do bem da família. Que a gente seja uma célula social, realmente respeitada, uma célula da sociedade realmente ativa, uma célula da sociedade que realmente cumpra a sua função: função de serem pessoas do bem. (Joana)

Joana ultrapassa a noção de individualidade, de proteção dos membros da família, mas sinaliza a função social da entidade familiar: ser pessoas do bem e colaborar com o bem-estar das pessoas. Considerando a família como "célula básica" da sociedade, sem dúvida, ela continua se afirmando como unidade social indiscutível (Roudinesco, 2003). Mesmo, porém, que a família tenha feito parte de praticamente todas as sociedades, sendo uma instituição universal, diversos estudiosos desse tema consideram-na uma formação social, na qual os laços familiares permanentes não são condicionados por necessidades biológicas, mas por determinantes culturais (Castells, 1996/2010).

A concepção de Patrícia enfatiza outro entendimento de família: família como um espaço intersubjetivo, uma comunidade que se edifica na relação de ajuda mútua entre os seus membros.

Eu vejo uma família como uma comunidade de pessoas que tem um laço afetivo, e que se ajudam e que só existe sentido da família existir se essas pessoas conseguem desenvolver a relação que une todo mundo que é amizade. Eu acho que tem que ter esse laço (...) e essa deve ser a linguagem. (Patrícia)

A concepção de Patrícia acerca da família fala, exatamente, do modo de vivenciar a sua vida familiar. Um viver em comunidade, cuja diversidade de papéis é marca que assinala a sua família: é mãe, tia biológica e madrinha do filho. O pai do filho, seu irmão, é cunhado da sua ex-esposa. Seu filho tem um pai e duas mães. O mesmo procede com a enteada de Patrícia: tem um pai, é enteada de Patrícia e tem uma mãe biológica. Novos personagens, como novas funções e estilos muito próprios de funcionamento se inscrevem nesse palco familiar e definem o modo de ser família de Patrícia.

A concepção de família da participante Maria, por sua vez, expressa o que muitos estudiosos da homoparentalidade enfatizam: em vários aspectos, esse arranjo familiar não se diferencia de outras formas de organização familiar (Grossi, 2003; Uziel, Mello, \& Grossi, 2006).

A gente se considera uma família normal. Por que eu digo uma familia normal? Porque antes do meu casamento com a Joana, eu tive um casamento heterossexual, e o meu casamento de hoje não muda em nada do outro. Quer dizer, mudar, muda. Porque eu aprendi com o primeiro e hoje eu tento não errar no segundo. Mas a questão prática, ela é igual. (Maria)

Todavia, mesmo que existam aspectos comuns nas práticas e dinâmicas entre as dinâmicas familiares (homossexuais e heterossexuais), é importante destacar que a família homoparental não é uma simples adaptação ou um ajuste de modelos familiares; afinal, cada família é única e, assim, precisa ser analisada (Fonseca, 2008; Passos, 2005). É consenso na literatura que um marcador diferencial das famílias homoparentais em relação às famílias heterossexuais refere-se ao preconceito e sofrimento que aquelas vivenciam (Rodriguez \& Paiva, 2009; Uziel, 2007).

Por meio das falas das participantes, pode-se perceber que as famílias devem ser descritas a partir de suas ações cotidianas, bem como das relações que se estabelecem entre os seus membros. As entrevistadas conceituaram a família como unidades intersubjetivas criadas e mantidas através do conjunto de relacionamentos vivenciados na prática. Definiram a família, portanto, como uma instituição que provê afeto, cuidado e proteção, além de ter a função de formação social dos seus membros. Percebe-se, portanto, que não é possível encontrar uma concepção única acerca da família, o que, por sua vez, conduz à necessidade do uso dos termos famílias e homoparentalidades (Gato, 2014; Wagner et al., 2011)

\section{Do Contrato de União Estável ao Casamento}

O relato das entrevistadas evidencia um dado expressivo: todas elas possuíam um contrato de união estável com as suas parceiras, sendo que com uma das participantes, Simone, este já foi homologado como casamento civil. Ou seja, todas elas buscaram o reconhecimento jurídico para as suas relações familiares (Castro, 2007; Rios, 2011).

Algumas participantes afirmaram que este contrato de união estável teve valor relacionado à garantia de direitos e proteção aos membros da família:

O contrato de união estável é uma formalidade perante a sociedade. Então a gente resolveu fazer o contrato de união estável, assim meio que às avessas. Porque a Joana ia fazer uma viagem, tava com medo de morrer. E ai ela dizia: "mas, olhe, se eu morrer, você tem direito a tudo!" (Maria)

Se eu tivesse morrido, como é que iriam ficar as crianças? [refere-se ao episódio de violência homofóbica que vivenciou] (...) foi pra gente assegurar os direitos das crianças. Assim, no caso da morte, eles não iam ficar desprevenidos. (Simone)

$\mathrm{O}$ reconhecimento da união civil de pessoas do mesmo sexo é alvo de uma complexa discussão jurídica e social. De acordo com Rios (2011), tal reconhecimento e legitimação representa, para alguns, o colapso das instituições e da moral que sedimenta e possibilita a vida em sociedade, ou, ainda, uma tentativa de normatização das famílias homoparentais à norma heterossexista. Para outros, está atrelado ao potencial de mudanças e transformações familiares e nada mais é do que "a exigência inevitável dos princípios democráticos" (Rios, 2011, p. 69). Ressalta-se, todavia, que a oficialização jurídica do casamento pode oferecer efeitos positivos na promoção do bem-estar físico e psicológico aos casais do mesmo sexo promovendo benefícios tangíveis às suas vidas (Wigth, LeBlanc, \& Badgett, 2013), o que pode colaborar para o exercício saudável da parentalidade. Assim sendo, os efeitos positivos da legalização estão relacionados aos benefícios econômicos tangíveis; ao senso de estabilidade 
no relacionamento associado com o reconhecimento legal do compromisso matrimonial; aos efeitos positivos de intimidade e proximidade; bem como ao maior apoio emocional e autoestima, geralmente vinculados ao casamento.

A aceitação social também aparece como uma justificativa significativa para a valorização da oficialização do casamento:

A gente acha que o casamento vai ser importante para o

Pedro, que vai estrear numa sociedade cheia de preconceito e

já vai estrear com duas coisas que não são comuns de se ver.

Ou, pelo menos, eu acho que não são, a gente não vê todo dia assim casais homossexuais e filhos adotados. Então, as mães serem casadas, eu acho que pra ele vai ter um significado bacana. (Maria)

Sem perder o caráter histórico que interpela as vivências familiares destas mulheres, resgata-se o fato de que a identidade lésbica foi edificada sob condições adversas, marcada pelo estigma do diferente e da "anormalidade" e pela discriminação social - exatamente por desafiar a ordem da complementaridade dos sexos, predominante na matriz heterossexista (Almeida \& Heilborn, 2008; Mello, 2005). Em razão do preconceito sexista, muitas famílias homoparentais ainda se mantêm na clandestinidade, sendo que as crianças parecem ser as principais vítimas dessa cultura homofóbica (Passos, 2005). A busca pela aceitação social, mediante a legalização das relações familiares, passa a compor o cenário da vida das mulheres lésbicas.

A fala de Maria, porém, além de revelar que a legalização do casamento pode proteger o filho da discriminação social, implica, também, num processo de normalização da sua família pelos caminhos do sistema heterossexista - amorcasamento-família (Castro, 2007; Mello, 2005; Roudinesco, 2003). Ao estar casada juridicamente, a entrevistada acredita que poderia oferecer um espaço de legitimação e normatização social para o filho.

Os depoimentos das participantes evidenciam, muitas vezes, os conflitos/paradoxos que essas mulheres vivenciaram para viabilizar o seu projeto de constituir uma família, pois, ao mesmo tempo em que estabelecem rupturas com a lógica heterossexista e avançam em direção ao projetos homoparentais, em outros momentos, revelam também dar continuidade aos valores estabelecidos pelas normas heterossexistas (Almeida, 2012; Uziel, 2007). No entanto, questiona-se: seria possível que essas mulheres não retomassem os valores da família nuclear, uma vez que elas estão mergulhadas nessa cultura patriarcal e heterossexista? Além disso, não se deve esquecer que elas nasceram em famílias tradicionais, compostas por um pai, uma mãe e filhos, sendo esse modelo uma referência importante para as suas vidas. Compreende-se, dessa forma, que o projeto familiar e conjugal das entrevistadas se forjou, exatamente, no embate entre as singularidades - pertinentes ao modo como elas se apropriaram de suas escolhas - e nas territorialidades fixas, sustentadas pela lógica da diferenciação sexual e da biologia como fundamentos epistemológicos das relações familiares e sociais. Foi, portanto, no âmbito dessa complexidade que as participantes avançaram na direção das suas relações homoparentais.

\section{Considerações Finais}

$\mathrm{O}$ artigo teve como objetivo investigar as concepções e modos de viver em família de mulheres lésbicas que têm filhos. Nesse sentido, foram geradas três categorias de análise. Na primeira delas, estratégias de acesso à parentalidade, observou-se que as concepções de família e parentalidade mostraram-se, por vezes, contraditórias: por um lado, as mulheres desnaturalizaram a ideia de procriação biológica como o único caminho para exercer a maternidade e elegeram a adoção como estratégia para se tornarem mães; por outro, percebeu-se que algumas mulheres procuraram um pai biológico para seus filhos, no sentido de legitimar e naturalizar o binarismo heterossexual e ainda privilegiar a consanguinidade no vínculo parental. Na segunda categoria, sobre definições de família, as entrevistadas colocaram acento na afetividade como o fundamento que rege as relações familiares, bem como a descreveram como um espaço de cuidado, proteção e de formação social dos seus membros. Por fim, a terceira categoria, mostrou que todas as participantes recorreram à legalização do casamento, mas que, ambiguamente, esse processo de reconhecimento legal foi, ao mesmo tempo, uma forma de legitimar socialmente as suas famílias, garantir direitos sociais e jurídicos e conseguir maior aceitação social.

A partir desses resultados, percebe-se quão contraditórias, plurais e complexas são as concepções e modos de viver em família: por um viés, compreendeu-se que essas famílias desconstroem a noção naturalizada do heterossexismo inscrita na ordem social e impõem as próprias marcas inventadas no fazer diário. Por outro, em muitos momentos, as participantes se enlaçam no entorno ideal de família nuclear e parecem dar continuidade à ideologia heterossexista e patriarcal. Ressalta-se, no entanto, que as famílias homoparentais, assim como qualquer arranjo familiar, são um espaço permeado por contradições, paradoxos e ambiguidades, de forma que estão sempre por se construir. Tais contradições, todavia, não são vistas aqui por um viés moralista dicotômico - certo ou errado; bom ou ruim - nem mesmo apontam para uma incongruência dos relatos das entrevistadas. Sinalizam a pluralidade/diversidade dessas famílias e, consequentemente, a inviabilidade de uma descrição única das famílias homoparentais.

Alguns limites se impuseram nesse estudo e merecem ser destacados a fim de nortear futuras investigações. Primeiramente, foi dado destaque apenas à percepção das mães acerca da concepção e dos modos de viver em família. É recomendável, portanto, que outras pesquisas relativas ao tema da homoparentalidade sejam efetivadas, envolvendo a compreensão de todos os integrantes da família, por exemplo, dos filhos e da família extensa. Outra perspectiva que se abre é a investigação da homoparentalidade masculina, das famílias compostas por transexuais ou, mesmo, das famílias de casais do mesmo sexo que recorreram às tecnologias reprodutivas para viabilizarem o seu projeto de paternidade/ maternidade.

Apesar desses limites, as vivências narradas pelas entrevistadas tornam-se relevantes por dar voz às mulheres lésbicas e visibilizar os arranjos familiares homoparentais. Ademais, colaboram para a revisão de conceitos rígidos e estereotipados que atravessam o imaginário social sobre as 
famílias e que acabam por alimentar o preconceito na vida daqueles que não se enquadram nesse modelo cristalizado de família tradicional.

\section{Referências}

Almeida, G., \& Heilborn, M. L. (2008). Não somos mulheres gays: Identidade lésbica na visão de ativistas brasileiras. Gênero, 9(1), 225-249.

Almeida, M. R. (2012). Os processos subjetivos no acolhimento e na adoção de crianças por casal homoafetivo: Um estudo de caso (Tese de Doutorado). Universidade de São Paulo, São Paulo, SP, Brasil.

Amatuzzi, M. (1993). Etapas do processo terapêutico: Um estudo exploratório. Psicologia e Pesquisa, 9, 1-21.

Arán, M., \& Corrêa, M. V. (2004). Sexualidade e política na cultura contemporânea: $\mathrm{O}$ reconhecimento social e jurídico do casal homossexual. Physis, 14(2), 329-341.

Badinter, E. (1985). Um amor conquistado. O mito do amor materno. Rio de Janeiro: Nova Fronteira.

Ben-Ari, A., \& Livni, T. (2006). Motherhood is not a given thing: Experiences and constructed meanings of biological and nonbiological lesbian mothers. Sex Roles, 54, 521-531. doi: 10.1007/s11199-006-9016-0

Biblarz, T. J., \& Savci, E. (2010). Lesbian, gay, bisexual, and transgender families. Journal of Marriage and Family, 72(3), 480-497. doi: 10.1111/j.1741-737.2010.00714.x

Butler, J. (2003). O parentesco é sempre tido como heterossexual? Cadernos Pagu, 21, 219-269.

Castells, M. (2010). O poder da identidade. São Paulo: Paz e Terra. (Original publicado em 1996)

Castro, R. B. (2007). Amor e ódio em relações 'conjugays'. In M. Grossi, A. P. Uziel \& L. Mello (Orgs.), Conjugalidades, parentalidades e identidades lésbicas, gays e travestis (pp. 89-107). Rio de Janeiro: Garamond.

Corrêa, M. E. C. (2012). Duas Mães? Mulheres Lésbicas e Maternidade (Tese de Doutorado). Universidade de São Paulo/ Faculdade de Saúde Pública, São Paulo, SP, Brasil.

Costa, J. F. (1992). A inocência e o vício: Estudos sobre homoerotismo. Rio de Janeiro: Relume-Dumará.

Donavan, C. (2000). Who needs a father? Negotiating biological fatherhood in british lesbian families using self-insemination. Sexualities, 3(2), 149-164. doi: 10.1177/136346000003002003

Fonseca, C. (2008). Homoparentalidade: Novas luzes sobre o parentesco. Estudos Feministas, 16(3), 424, 769-783.

Gato, J. (2014). Homoparentalidades: Perspetivas psicológicas. Coimbra: Almedina

Goldberg, A. E., \& Gartrell, N. K. (2014). LGB-parent families: The current state of the research and directions for the future. Advances in Child Development and Behavior, 46,57-88. doi:10.1016/B978-0-12-800285-8.00003-0

Grossi, M. P. (2003). Gênero e parentesco: Famílias gays e lésbicas no Brasil. Cadernos Pagu, 21(24), 261-280.

Lira, A. N., \& Morais, N. A. (2016). Famílias constituídas por lésbicas, gays e bissexuais: revisão sistemática de literatura. Temas em Psicologia, 24(3), 1051-1067. doi: 10.9788/ TP2016.3-14Pt
Machin, R. (2016). Homoparentalidade e adoção: (Re) afirmando seu lugar como família. Psicologia \& Sociedade, 28(2), 350359. doi:10.1590/1807-03102016v28n2p350

Meletti, A. T., \& Scorsolini-Comin, F. (2015). Conjugalidade e expectativas em relação à parentalidade em casais homossexuais. Psicologia: Teoria e Prática, 17(1), 37-49.

Mello, L. (2005). Novas famílias: Conjugalidades homossexual no Brasil contemporâneo. Rio de Janeiro: Garamond.

Moreira, V. (2004). O método fenomenológico de Merleau-Ponty como ferramenta crítica na pesquisa em psicopatologia. Psicologia: Reflexão e Crítica, 17(3), 447-456.

Passos, M. C. (2005). Nem tudo que muda, muda tudo: Um estudo sobre as funções da família. In T. Féres-Carneiro (Org.), Família e casal - efeitos da contemporaneidade (pp. 11-23). Rio de Janeiro: PUC-Rio.

Perrot, M. (1993). O nó e o ninho. In D. Varella, R. Campos \& M. Tas (Orgs.), Veja 25 anos - Reflexões para o futuro (pp. 74-81). São Paulo: Editora Abril.

Pontes, M. F., Féres-Carneiro, T., \& Magalhães, A. S. (2015). Homoparental families and biological motherhood. Psicologia \& Sociedade, 27(1), 189 198. doi: 10.1590/1807-03102015v27n1p189

Rios, R. R. (2011). Direitos sexuais, uniões homossexuais e a decisão do Supremo Tribunal Federal (ADPF No 132 - RJ e ADI 4.277). In R. Rios, C. Golin \& P. G. C. Leivas (Orgs.), Homossexualidade e direitos sexuais: Reflexões a partir da decisão do STF (pp. 69-114). Porto Alegre: Sulina.

Rodriguez, B. C., \& Paiva, M. L. S. C. (2009). Um estudo sobre o exercício da parentalidade em contexto homoparental. Revista do NESME, 1(6), 13-27.

Roudinesco, E. (2003). A família em desordem. Rio de Janeiro: Zahar.

Santos, Y. G. S., Scorsolini-Comin, F., \& Santos, M. A. (2013). Homoparentalidade masculina: Revisando a produção científica. Psicologia: Reflexão e Crítica, 26(3),572-582. doi:10.1590/S0102-79722013000300017

Szymanski, H. (1998). Significados de família. In G. Loch \& M. A Yunes (Orgs.), A família que se pensa e a família que se vive (pp. 9-17). Rio Grande: Fundação Universidade Federal do Rio Grande.

Tarnovski, F. (2010). Etre père et homosexuel dans la France contemporaine (Doctoral Dissertation). Toulouse, EHESS.

Tarnovski, F. L. (2004). Pai é tudo igual? Significados da paternidade para homens que se autodefinem como homossexuais. In A. Piscitelli, M. F. Gregori \& S. Carrara (Orgs.), Sexualidades e saberes: Convenções e fronteiras (pp. 385-414). Rio de Janeiro: Garamond.

Uziel, A. P. (2007). Homossexualidade e adoção. Rio de Janeiro: Garamond.

Uziel, A. P., Mello, L., \& Grossi M. (2006). Conjugalidades e parentalidades de gays, lésbicas e transgêneros no Brasil. Revista Estudos Feministas, 14(2), 535-547. doi: 10.1590/ S0104-026X2006000200008

Vespucci, G. (2014). Una fórmula deseable: el discurso "somos familias" como símbolo hegemónico de las reivindicaciones gay-lésbicas. Sexualidad, Salud y Sociedad (Rio de Janeiro), (17), 30-65. Epub May 00, 2014. doi: 10.1590/1984-6487. sess.2014.17.05.a 
Vilhena, J. D., Souza, A. C. B. D., Uziel, A. P., Zamora, M. H., \& Novaes, J. V. (2011). Que família? Provocações a partir da homoparentalidade. Revista Mal Estar e Subjetividade, 11(4), $1639-1658$.

Wagner, A., Tronco, C., \& Armani, A. B. (2011). Os desafios da família contemporânea: Revisitando conceitos. In A. Wagner (Org.), Desafios psicossociais da família contemporânea: Pesquisa e reflexões (pp. 19-35). Porto Alegre: Artmed.

Weston, K. (1991). Families we choose: Lesbians, gays, kinship. New York, NY: Columbia University Press.
Wight, R. G., LeBlanc, A. J., \& Lee Badgett, M. V. (2013). Samesex legal marriage and psychological well-being: Findings from the California Health Interview Survey. American Journal of Public Health, 103(2), 339-346. doi:10.2105/ AJPH.2012.301113

Zambrano, E. (2006). Parentalidades impensáveis: Pais/mães homossexuais, travestis e transexuais. Horizonte Antropológico, 12(26), 123-147. doi: 10.1590/S0104-71832006000200006 